\title{
NUDT15 gene variants and thiopurine-induced leukopenia in patients with inflammatory bowel disease
}

\author{
Katsuyoshi Matsuoka \\ Division of Gastroenterology and Hepatology, Department of Internal Medicine, Toho University Sakura Medical Center, Sakura, Japan
}

Thiopurine has been used to maintain remission and to reduce antidrug antibody formation in monoclonal antibody therapy in patients with inflammatory bowel disease (IBD). The use of thiopurine is limited by side effects such as leukopenia. Thiopurine S-methyltransferase (TPMT) variants are associated with thiopurine-induced leukopenia in Westerners, but the frequency of the risk alleles is low in Asians. Recently, a variant in the nudix hydrolase 15 (NUDT15) gene (R139C, c.415C > T) was reported to be associated with early severe leukopenia in Asians. NUDT15 is an enzyme that converts 6-thio-(deoxy)guanosine triphosphate (6-T(d)GTP) to 6-thio-(deoxy)guanosine monophosphate (6-T(d)GMTP). The R139C variant impairs the stability of the protein and increases incorporation of 6-TGTP and 6-TdGTP into RNA and DNA, respectively, resulting in leukopenia. The frequency of $\mathrm{C} / \mathrm{C}, \mathrm{C} / \mathrm{T}$, and $\mathrm{T} / \mathrm{T}$ are approximately $80 \%, 20 \%$, and $1 \%$, respectively in East Asians. Early leukopenia occurred in less than $3 \%$ of patients with $\mathrm{C} / \mathrm{C}$ and in around $20 \%$ of those with $\mathrm{C} / \mathrm{T}$, whereas it occurred in almost all patients with $\mathrm{T} / \mathrm{T}$. Patients homozygous for this variant also develop severe hair loss. The measurement of NUDT15 R139C can increase the safety of thiopurine dramatically and is a successful example of personalized medicine in the field of IBD. (Intest Res 2020;18:275-281)

Key Words: NUDT15; Thiopurine; Azathioprine; 6-Mercaptopurine

\section{INTRODUCTION}

A purine analogue, 6-mercaptopurine (6-MP), initially developed as a treatment for acute leukemia, ${ }^{1}$ was found to have immunosuppressive properties. ${ }^{2}$ Then, azathioprine (AZA), a prodrug of 6-MP, was first used to treat IBD in $1966 .{ }^{3}$ In patients with IBD, thiopurine has been used to maintain remission and, more recently, to reduce the production of antidrug antibodies in monoclonal antibody therapy. It is also used to treat other autoimmune diseases such as autoimmune hepatitis and systemic lupus erythematosus.

Despite the therapeutic efficacy of thiopurine in IBD, its use is limited because it may cause severe side effects such as leu-

Received January 8, 2020. Revised March 21, 2020. Accepted April 12, 2020. Correspondence to Katsuyoshi Matsuoka, Division of Gastroenterology and Hepatology, Department of Internal Medicine, Toho University Sakura Medical Center, 564-1 Shimoshizu, Sakura 285-8741, Japan. Tel: +81-43-462-8811, Fax: +81-43-487-4246, E-mail: katsuyoshi.matsuoka@med.toho-u.ac.jp kopenia, which is more common in Asians than Westerners. The incidence of leukopenia is $15 \%$ to $40 \%$ in Asians, ${ }^{4-6}$ who seem to be more susceptible to thiopurine-induced leukopenia because the incidence of myelosuppression (including leukopenia, thrombocytopenia, and anemia) in Westerners is approximately $3 \%{ }^{7,8}$ In particular, severe leukopenia occurs in approximately $1 \%$ of Asian patients early after starting thiopurine. ${ }^{9}$ Therefore, while Western guidelines recommend the dose of AZA between 2 and $2.5 \mathrm{mg} / \mathrm{kg},{ }^{10}$ Asian guidelines recommend starting with a lower dose of $25 \mathrm{mg}{ }^{11}$ In Westerners, thiopurine S-methyltransferase (TPMT) gene variants (TPMT*2, ${ }^{*} 3 \mathrm{~A},{ }^{*} 3 \mathrm{~B},{ }^{*} 3 \mathrm{C}$ ) are known to be associated with leukopenia. TPMT is one of the metabolizing enzymes of thiopurine. It is recommended that the dose of thiopurine be adjusted according to the TPMT gene variants. ${ }^{12}$ In Asians, however, the allele frequency of the TPMT variants was only approximately $3 \%,{ }^{13-16}$ and the TPMT variants alone do not predict leukopenia.

In 2014, a genome-wide association study in Korean IBD 
patients reported that a variant of the nudix (nucleoside diphosphate-linked moiety X)-type motif 15 (NUDT15) or nudix hydrolase 15 (official name) gene was associated with thiopurine-induced early leukopenia. ${ }^{16}$ This variant (rs116855232) replaces arginine at position 139 of the protein with cysteine (R139C; p.Arg139Cys; c.415C > T). Almost simultaneously, a correlation between this NUDT15 gene variant and acute severe leukopenia caused by thiopurine was reported in Japanese patients with acute lymphocytic leukemia. ${ }^{17}$

\section{METABOLISM OF THIOPURINE}

Orally administered AZA is absorbed from the gut and metabolized nonenzymatically to 6-MP in the body, which is then inactivated by both methylation and oxidation intracellularly (Fig. 1). ${ }^{18}$ TPMT is an enzyme that methylates and inactivates 6-MP to 6-methy-MP (6-MeMP). Xanthine oxidase (XO) metabolizes 6-MP to 6-thio-uric acid. 6-MP is eventually metabolized to 6-thio-guanine nucleotides (6-TGN). 6-TGN is a ge- neric name for 6-thio-guanosine monophosphate (6-TGMP), 6-thio-guanosine diphosphate (6-TGDP), and 6-thio-guanosine triphosphate (6-TGTP). ${ }^{19}$ 6-TGDP is reduced to 6-thiodeoxyguanosine diphosphate (6-TdGDP), which is further phosphorylated to 6-thio-deoxyguanosine triphosphate (6-TdGTP). 6-TGTP is incorporated into RNA and 6-TdGTP into DNA, causing inhibition of RNA transcription and DNA replication, respectively, and leading to apoptosis of the cell. 6-TGTP also causes apoptosis of lymphocytes by inhibiting GTPase Racl. ${ }^{20}$ In this metabolic pathway, reduced TPMT activity due to the genetic variants leads to increased 6-TGN levels and causes leukopenia.

\section{ROLE OF NUDT15}

The function of NUDT15 was unknown when the correlation between its gene variants and thiopurine-induced leukopenia was reported. It was reported that the NUDT15 gene variant was not correlated with 6-TGN levels, ${ }^{9}$ suggesting that NUDT15

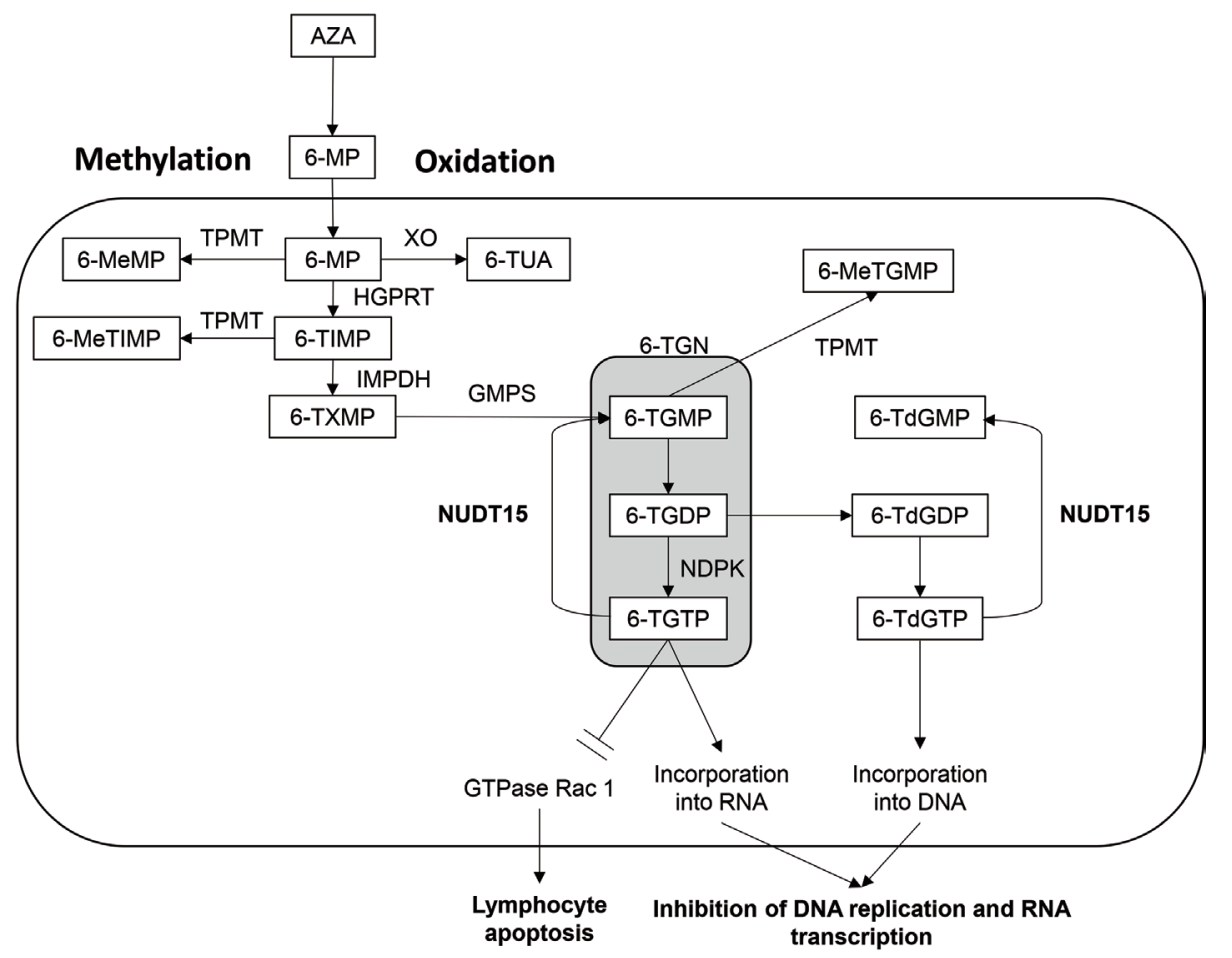

Fig. 1. Metabolism of thiopurine. ${ }^{12,18,22,39}$ 6-MeMP, 6-methyl-mercaptopurine; 6-MeTGMP, 6-methyl-thio-guanosine monophosphate; 6-MeTIMP, 6-methyl-thio-inosine monophosphate; 6-MP, 6-mercaptopurine; 6-TdGDP, 6-thio-deoxyguanosine diphosphate; 6-TdGMP, 6-thio-deoxyguanosine monophosphate; 6-TdGTP, 6-thio-deoxyguanosine triphosphate; 6-TGDP, 6-thio-guanosine diphosphate; 6-TGMP, 6-thio-guanosine monophosphate; 6-TGN, 6-thio-guanine nucleotides; 6-TGTP, 6-thio-guanosine triphosphate; 6-TIMP, 6-thioinosine monophosphate; 6-TXMP, 6-thio-xanthosine monophosphate; 6-TUA, 6-thio-uric acid; AZA, azathioprine; GMPS, guanosine monophosphate synthetase; HGPRT, hypoxanthine-guanine phosphoribosyltransferase; IMPDH, inosine monophosphate dehydrogenase; NDPK, nucleotide-diphosphate kinase; TPMT, thiopurine S-methyltransferase; X0, xanthine oxidase; NUDT15, nudix hydrolase 15. 


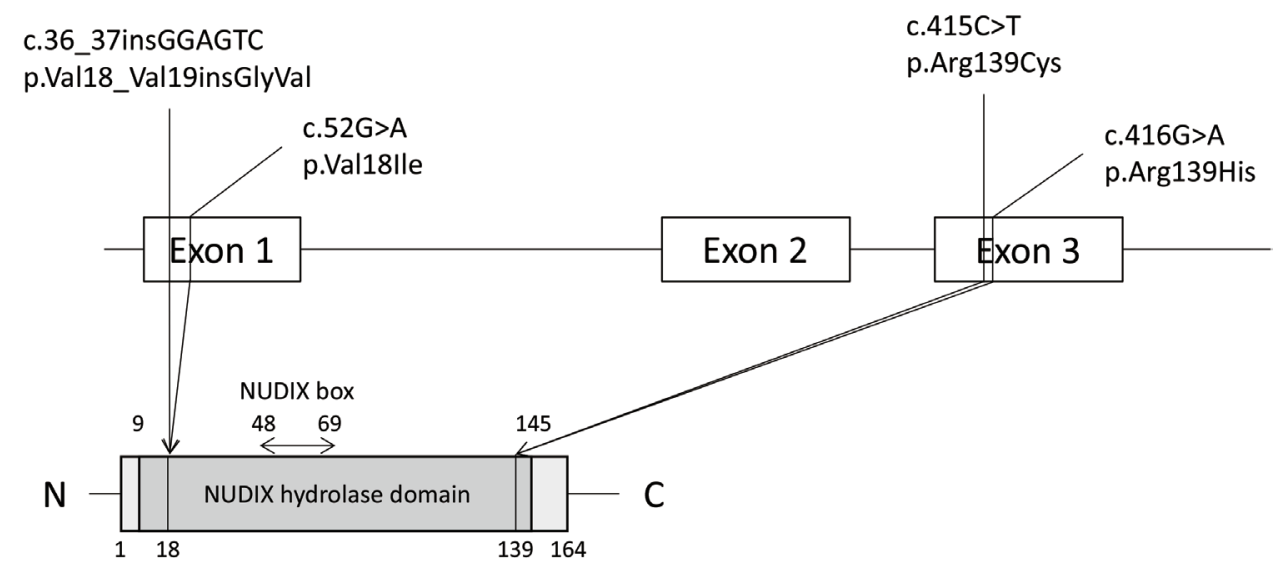

Fig. 2. Nudix hydrolase 15 (NUDT15) gene and protein structure. ${ }^{23,37}$

causes leukopenia independently of 6-TGN levels. Then, NUDT15 was found to be an enzyme that hydrolyzes 6-T(d) GTP to 6-T(d)GMP (Fig. 1). ${ }^{21,22}$ The NUDT15 gene is consisted of 3 exons and belongs to the NUDIX hydrolase family, which has the highly conserved NUDIX box and hydrolyzes nucleoside diphosphate liked to any moiety to nucleoside monophosphate (Fig. 2) ${ }^{23}$ Unlike the other NUDIX family proteins, the NUDT15 protein forms a homodimer. ${ }^{21}$

The NUDT15 R139C variant impairs stabilization of its catalytic site and causes conformational change of the protein. ${ }^{22,24}$ Thus, the variant in the NUDT15 gene reduces its enzymatic activity and increase the levels of 6-TGTP and 6-TdGTP. They are incorporated into RNA and DNA, respectively, causing leukopenia. These results can explain that the NUDT15 R139C gene variant does not correlate with 6-TGN levels because 6-TGN measures 6-TGMP, 6-TGDP, and 6-TGTP collectively. in vivo, administration of 6-MP to NUDT15 knockout mice increased the incorporation of 6-TdGTP into DNA. ${ }^{25}$ In mice with the homologous mutation corresponding to the human NUDT15 R139C variant, a high dose of 6-MP (2 mg/ kg) damages hematopoietic stem cells and progenitor cells and causes lethal leukopenia. ${ }^{26}$

NUDT15 is an important enzyme in the metabolism of thiopurine, but its physiological function in vivo is still unknown. NUDT15 can hydrolyze 8-oxo-dGTP, one of the most common oxidative dNTP generated by oxidative stress and a potent mutagenic substrate for DNA synthesis, to 8-oxo-dGDP or 8-oxo-dGMP, ${ }^{27}$ but this effect of NUDT15 is of minor importance in vivo because depletion of NUDT15 has no effect on incorporation of 8-oxo-dGTP into DNA in vivo. ${ }^{21}$
Table 1. Frequency of the NUDT15 R139C Variant

\begin{tabular}{|c|c|c|c|c|c|}
\hline Author & Country & No. & $\mathrm{c} / \mathrm{C}$ & $\mathrm{C} / \mathrm{T}$ & $\mathrm{T} / \mathrm{T}$ \\
\hline $\begin{array}{l}\text { Chang } \\
\text { et al. }\end{array}$ & Korea & 145 & $105(72.4)$ & 38 (26.2) & $2(1.4)$ \\
\hline $\begin{array}{l}\text { Lee } \\
\text { et al. }{ }^{29}\end{array}$ & Korea & CD 165 & $106(64.2)$ & 28 (17.0) & $6(3.6)$ \\
\hline $\begin{array}{l}\text { Asada } \\
\text { et al. }\end{array}$ & Japan & $\begin{array}{l}264 \\
\text { UC } 89 \\
\text { CD } 72 \\
\text { HC } 103\end{array}$ & $213(80.7)$ & 48 (18.2) & $2(1.1)$ \\
\hline $\begin{array}{l}\text { Kakuta } \\
\text { et al. }^{30}\end{array}$ & Japan & $\begin{array}{l}135 \\
\text { CD } 111 \\
\text { UC } 23 \\
\text { IBDU } 1\end{array}$ & $107(79.3)$ & 23 (17.0) & $5(3.7)$ \\
\hline $\begin{array}{l}\text { Sato } \\
\text { et al. }{ }^{31}\end{array}$ & Japan & $\begin{array}{l}160 \\
\text { CD } 86 \\
\text { UC } 72 \\
\text { IBDU } 1 \\
\text { BD } 1\end{array}$ & $117(73.1)$ & 35 (21.9) & $8(5.0)$ \\
\hline 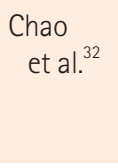 & China & $\begin{array}{l}732 \\
\text { CD } 660 \\
\text { UC } 60 \\
\text { IBDU } 12\end{array}$ & 557 (76.1) & $164(22.4)$ & $11(1.5)$ \\
\hline $\begin{array}{l}\text { Sutiman } \\
\text { et al. }{ }^{33}\end{array}$ & $\begin{array}{l}\text { Singapore } \\
\text { Chinese }(65.1 \%) \\
\text { Malay }(9.3 \%) \\
\text { Indian }(24.0 \%) \\
\text { Others }(1.6 \%)\end{array}$ & $\begin{array}{l}129 \\
\text { CD } 89 \\
\text { UC } 40\end{array}$ & $111(86.0)$ & 16 (12.4) & $2(1.6)$ \\
\hline $\begin{array}{l}\text { Shah } \\
\text { et al. }^{34}\end{array}$ & India & $\begin{array}{l}69 \\
\text { UC } 34 \\
\text { CD } 24 \\
\text { AlH } 11\end{array}$ & 60 (87.0) & $8(11.6)$ & $1(1.4)$ \\
\hline
\end{tabular}

Values are presented as number (\%).

NUDT15, nudix hydrolase 15; HC, healthy control; IBDU, IBD unclassified; $\mathrm{BD}$, Behçet's disease; AlH, autoimmune hepatitis. 


\section{FREQUENCY OF NUDT15 GENE VARIANTS}

Table 1 shows the frequency of the NUDT15 R139C variant in Asians; the frequencies of $\mathrm{C} / \mathrm{C}, \mathrm{C} / \mathrm{T}$, and $\mathrm{T} / \mathrm{T}$ are approximately $80 \%, 20 \%$, and $1 \%-5 \%$, respectively. ${ }^{9,28-34}$ It should be noted that most of the studies are retrospective and may overestimate the frequency of $\mathrm{T} / \mathrm{T}$. The only prospective study by Chang et $\mathrm{al}^{28}$ reported that the frequency of $\mathrm{T} / \mathrm{T}$ is $1.2 \%$.

The NUDT15 R139C variant is also found in South Americans with Native American ancestry. ${ }^{35}$ However, in the Middle East, the frequency of this variant is less than one-tenth of East Asians. ${ }^{36}$ The frequency of the NUDT15 R139C variant is also extremely low in Europeans and Africans, ${ }^{37}$ however, the allele frequency of another variant of the NUDT15 gene, p.Gly17 Val18del, is observed at about $2 \%$ in Europeans. This variant was also reported to correlate with thiopurine-induced leukopenia. ${ }^{38}$
To date, several variants have been reported in the NUDT15 gene, of which 4 variants (c.36_37insGGAGTC, c.52G > A, c.415C > T, c.416G > A) are mainly observed (Fig. 2). Six haplotypes combining these variants are reported (Table 2). ${ }^{37}$ The haplotypes carrying p.Arg139Cys $(* 2, * 3)$ cause an extremely low enzymatic activity; the other variant haplotypes $\left({ }^{*} 4,{ }^{*} 5,{ }^{*} 6\right)$ results in an intermediate decrease in enzymatic activity. ${ }^{37,39}$ Other rare variants include p.Arg34Thr, p.Lys35Glu, p.Gly17_ Val18del, p.Met1Thr, p.Arg10Trp, and p.Gly47Arg. ${ }^{39}$ The effects of these variants on thiopurine-induced leukopenia have rarely been tested in patients with IBD.

\section{THIOPURINE-INDUCED EARLY SEVERE LEUKOPENIA AND NUDT15 GENE VARIANTS}

Table 3 presents the association between the incidence of early leukopenia and NUDT15 R139C variant in studies in which

Table 2. Haplotypes of NUDT15 Gene

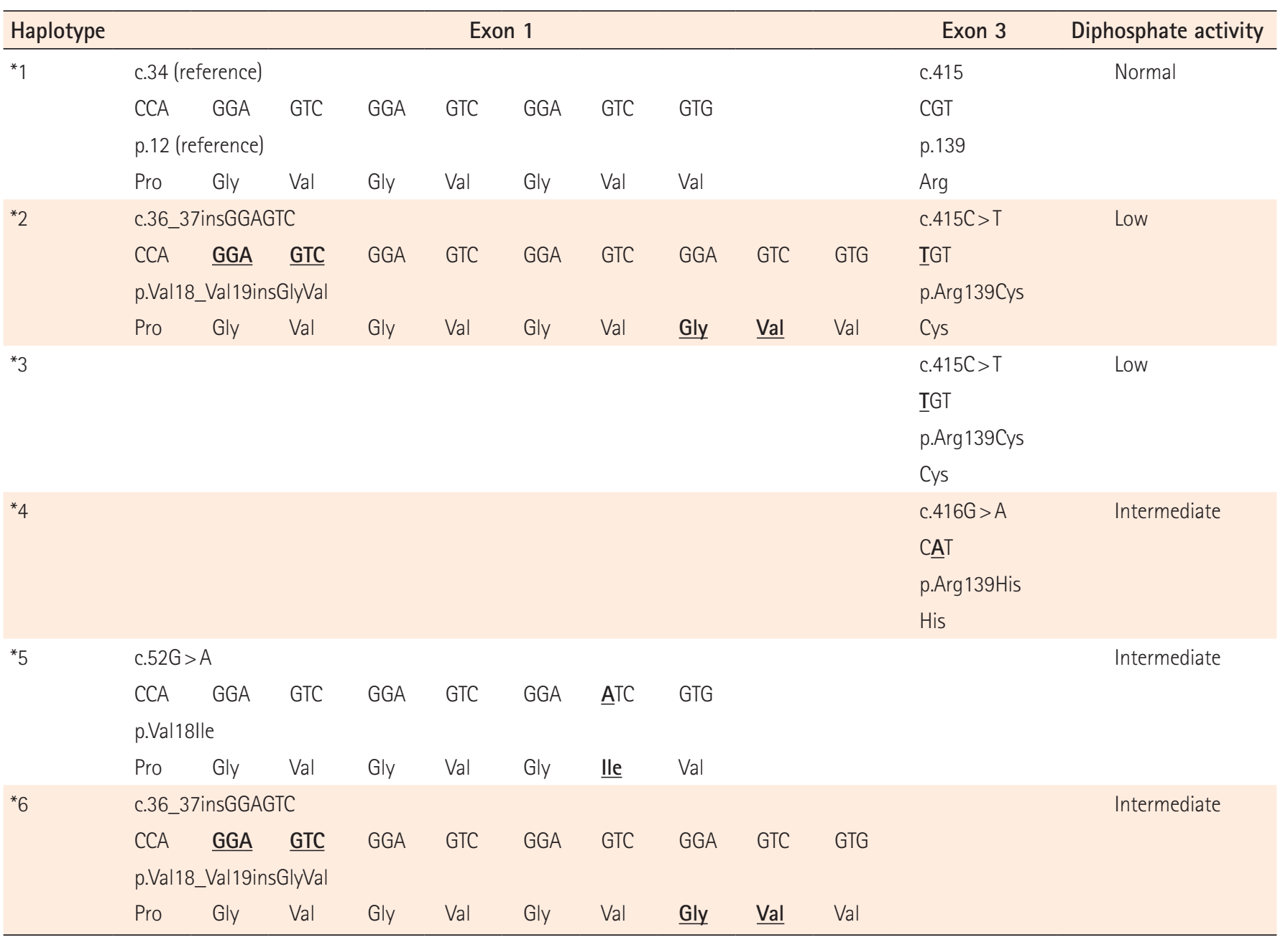


Table 3. Association between NUDT15 R139C Variant and Early Leukopenia

\begin{tabular}{lccc}
\hline Study & C/C & C/T & T/T \\
\hline Kakuta et al. $^{30}$ & $1 / 106(0.9)$ & $4 / 19(17.4)$ & $5 / 5(100)$ \\
Lee et al. $^{29}$ & 0.8 & 24.2 & 100 \\
Yang et al. $^{16}$ & $7 / 788(0.9)$ & $45 / 176(25.6)$ & $14 / 14(100)$ \\
Asada et al. $^{9}$ & $2 / 127(1.6)$ & $2 / 32(6.3)$ & $2 / 2(100)$ \\
Sato et al. $^{31}$ & $3 / 109(2.8)$ & $8 / 33(24.2)$ & $5 / 7(71.4)$ \\
\hline
\end{tabular}

Values are presented as number/number (\%) or percent. Early leukopenia is defined as white blood cell count less than $3,000 / \mathrm{mm}^{3}$ within 8 weeks after initiation of thiopurine.

NUDT15, nudix hydrolase 15.

early leukopenia was defined as a white bold cell count $<3,000$ cells $/ \mathrm{mm}^{3}$ within 8 weeks after initiation of thiopurine., ${ }^{9,16,29-31}$ Early leukopenia occurred in less than $3 \%$ of patients with $\mathrm{C} / \mathrm{C}$ and in around $20 \%$ of those with $\mathrm{C} / \mathrm{T}$, whereas it occurred in almost all patients with $\mathrm{T} / \mathrm{T}$. In addition to the R139C variant, a Chinese group reported that the c.36_37insGAGTC and c.52G $>$ A variants were also associated with leukopenia and the combination of these variants can predict leukopenia more accurately. ${ }^{32}$ The effects of variants other than R139C need to be further investigated.

A Korean prospective study confirmed the usefulness of measuring the NUDT15 R139C gene variant prior to thiopurine administration. ${ }^{28}$ In this study, 182 patients with IBD were randomly assigned to receive or not receive genetic testing (NUDT15, FTO [fat mass and obesity-associated protein], TPMT) prior to azathioprine administration. Azathioprine was started at $50 \mathrm{mg}$ and gradually increased to $2.0-2.5 \mathrm{mg} / \mathrm{kg}$ in patients with no genetic variant in the genotyping group and in those in the non-genotyping group. In patients homozygous for any risk variant, azathioprine was not recommended to be administered. The incidence of myelosuppression during the study period was significantly higher in the non-genotyping group than in the genotyping group (35.9\% vs. 16.7\%). The heterozygous NUDT15 variant was responsible for most of leukopenia.

Based on these accumulating evidence, the NUDT15 gene variant is described in the recent guideline as a test to be carried out before thiopurine administration. ${ }^{12}$ In Japan, the measurement of NUDT15 R139C variant was approved for clinical use in February 2019.

Thiopurine is contraindicated in patients with $\mathrm{T} / \mathrm{T}$; the optimal way to administer thiopurine in patients with $\mathrm{C} / \mathrm{T}$ remains undetermined. A large Japanese multicenter retro- spective study showed that the time to leukopenia was shorter and tolerated doses of thiopurine were lower in patients with $\mathrm{C} / \mathrm{T}$ or $\mathrm{T} / \mathrm{T}$ than those with $\mathrm{C} / \mathrm{C}{ }^{40}$ Another study demonstrated that the decrease in leukocyte and platelet count persisted longer (up to 6 months) in patients heterozygous for this variant than those without this variant. ${ }^{41}$ Careful monitoring of leukocyte counts over time is required in such patients.

\section{OTHER SIDE EFFECTS OF THIOPURINES AND NUDT15 GENE VARIANTS}

Thiopurine has also been associated with severe hair loss, a side effect not seen in Westerners, and unique to Asians. This severe hair loss is also associated with the NUDT15 R139C variant. ${ }^{30}$ Severe hair loss is unavoidable when taking thiopurine in patients homozygous for this variant (the incident rate is $100 \%) .^{30}$ It does not occur in patients without or heterozygous for the variant. Thus, severe thiopurine-induced hair loss completely depends on the homozygous NUDT15 gene variant. It was reported that gastrointestinal symptoms may also be associated with the NUDT15 variant. ${ }^{31}$ Other side effects including liver damage, pancreatitis, fever, and skin symptoms do not appear to be associated with the variant. ${ }^{40}$

\section{CONCLUSIONS}

Severe leukopenia and hair loss, the primary concerns in thiopurine administration in Asians, are almost completely predictable with the NUDT15 R139C gene variant. This discovery dramatically increased the safety of thiopurine. This represents an important successful example of personalized medicine in the field of IBD. Thiopurine, an old drug, is still a key remissionmaintaining medication in IBD. Measuring the NUDT15 R139C variant, use of thiopurine is expected to be optimized. In contrast, other side effects of thiopurine including liver damage, pancreatitis, and lymphoma cannot be prevented by the NUDT15 variant. Further research is needed to reduce these risks associated with thiopurine.

\section{FINANCIAL SUPPORT}

The authors received no financial support for the research, authorship, and/or publication of this article. 


\section{CONFLICT OF INTEREST}

Matsuoka K received lecture fees from Mitsubishi Tanabe Pharma, Takeda Pharmaceutical, Janssen Pharmaceutical, Abbvie, EA Pharma, Pfizer, Mochida Pharmaceutical, Kyorin Pharmaceutical, Zeria Pharmaceutical, Kissei Pharmaceutical, Nippon Kayaku, Thermo Fisher Scientific, Alfresa Pharma, JIMRO, Miyarisan Pharmaceutical; consultancy fees from Thermo Fisher Scientific, Alfresa Pharma, EA Pharma, Takeda Pharmaceutical, Janssen, Abbvie, Mitsubishi Tanabe Pharma; research grants from Mitsubishi Tanabe Pharma, Mochida Pharmaceutical, Abbvie, Takeda Pharmaceutical, Pfizer, Nippon Kayaku, Shionogi Pharmaceutical, EA Pharma, Zeria Pharmaceutical, Kissei Pharmaceutical.

\section{AUTHOR CONTRIBUTION}

Writing and approval of final manuscript: Matsuoka K.

\section{ORCID}

Matsuoka K https://orcid.org/0000-0002-2950-7660

\section{REFERENCES}

1. Burchenal JH, Murphy ML, Ellison RR, et al. Clinical evaluation of a new antimetabolite, 6-mercaptopurine, in the treatment of leukemia and allied diseases. Blood 1953;8:965-999.

2. Schwartz R, Stack J, Dameshek W. Effect of 6-mercaptopurine on antibody production. Proc Soc Exp Biol Med 1958;99:164167.

3. Bowen GE, Irons GV Jr, Rhodes JB, Kirsner JB. Early experiences with azathioprine in ulcerative colitis; a note of caution. JAMA 1966;195:460-464.

4. Takatsu N, Matsui T, Murakami Y, et al. Adverse reactions to azathioprine cannot be predicted by thiopurine S-methyltransferase genotype in Japanese patients with inflammatory bowel disease. J Gastroenterol Hepatol 2009;24:1258-1264.

5. Qiu Y, Mao R, Zhang SH, et al. Safety profile of thiopurines in Crohn disease: analysis of 893 patient-years follow-up in a Southern China Cohort. Medicine (Baltimore) 2015;94:e1513.

6. Kim JH, Cheon JH, Hong SS, et al. Influences of thiopurine methyltransferase genotype and activity on thiopurine-induced leukopenia in Korean patients with inflammatory bowel disease: a retrospective cohort study. J Clin Gastroenterol 2010; 44:e242-e248.
7. Sood R, Ansari S, Clark T, Hamlin PJ, Ford AC. Long-term efficacy and safety of azathioprine in ulcerative colitis. J Crohns Colitis 2015;9:191-197.

8. Lewis JD, Abramson O, Pascua M, et al. Timing of myelosuppression during thiopurine therapy for inflammatory bowel disease: implications for monitoring recommendations. Clin Gastroenterol Hepatol 2009; 7:1195-1201.

9. Asada A, Nishida A, Shioya M, et al. NUDT15 R139C-related thiopurine leukocytopenia is mediated by 6 -thioguanine nucleotide-independent mechanism in Japanese patients with inflammatory bowel disease. J Gastroenterol 2016;51:22-29.

10. Lamb CA, Kennedy NA, Raine T, et al. British Society of Gastroenterology consensus guidelines on the management of inflammatory bowel disease in adults. Gut 2019;68(Suppl 3): s1-s106.

11. Matsuoka K, Kobayashi T, Ueno F, et al. Evidence-based clinical practice guidelines for inflammatory bowel disease. J Gastroenterol 2018;53:305-353.

12. Relling MV, Schwab M, Whirl-Carrillo M, et al. Clinical Pharmacogenetics Implementation Consortium guideline for thiopurine dosing based on TPMT and NUDT15 genotypes: 2018 update. Clin Pharmacol Ther 2019;105:1095-1105.

13. Fangbin Z, Xiang G, Minhu C, et al. Should thiopurine methyltransferase genotypes and phenotypes be measured before thiopurine therapy in patients with inflammatory bowel disease? Ther Drug Monit 2012;34:695-701.

14. Collie-Duguid ES, Pritchard SC, Powrie RH, et al. The frequency and distribution of thiopurine methyltransferase alleles in Caucasian and Asian populations. Pharmacogenetics 1999;9: $37-42$.

15. Kumagai K, Hiyama K, Ishioka S, et al. Allelotype frequency of the thiopurine methyltransferase (TPMT) gene in Japanese. Pharmacogenetics 2001;11:275-278.

16. Yang SK, Hong M, Baek J, et al. A common missense variant in NUDT15 confers susceptibility to thiopurine-induced leukopenia. Nat Genet 2014;46:1017-1020.

17. Tanaka Y, Kato M, Hasegawa D, et al. Susceptibility to 6-MP toxicity conferred by a NUDT15 variant in Japanese children with acute lymphoblastic leukaemia. Br J Haematol 2015;171: 109-115.

18. Moon W, Loftus EV Jr. Review article: recent advances in pharmacogenetics and pharmacokinetics for safe and effective thiopurine therapy in inflammatory bowel disease. Aliment Pharmacol Ther 2016;43:863-883.

19. Lim SZ, Chua EW. Revisiting the role of thiopurines in inflammatory bowel disease through pharmacogenomics and use 
of novel methods for therapeutic drug monitoring. Front Pharmacol 2018;9:1107.

20. Tiede I, Fritz G, Strand S, et al. CD28-dependent Rac1 activation is the molecular target of azathioprine in primary human CD4+ T lymphocytes. J Clin Invest 2003;111:1133-1145.

21. Carter M, Jemth AS, Hagenkort A, et al. Crystal structure, biochemical and cellular activities demonstrate separate functions of MTH1 and MTH2. Nat Commun 2015;6:7871.

22. Valerie NC, Hagenkort A, Page BD, et al. NUDT15 hydrolyzes 6-thio-deoxyGTP to mediate the anticancer efficacy of 6-thioguanine. Cancer Res 2016;76:5501-5511.

23. Singh M, Bhatia $P$, Khera S, Trehan A. Emerging role of NUDT15 polymorphisms in 6-mercaptopurine metabolism and dose related toxicity in acute lymphoblastic leukaemia. Leuk Res 2017;62:17-22.

24. Man P, Fábry M, Sieglová I, Kavan D, Novák P, Hnízda A. Thiopurine intolerance-causing mutations in NUDT15 induce temperature-dependent destabilization of the catalytic site. Biochim Biophys Acta Proteins Proteom 2019;1867:376-381.

25. Nishii R, Moriyama T, Janke LJ, et al. Preclinical evaluation of NUDT15-guided thiopurine therapy and its effects on toxicity and antileukemic efficacy. Blood 2018;131:2466-2474.

26. Tatsumi G, Kawahara M, Imai T, et al. Thiopurine-mediated impairment of hematopoietic stem and leukemia cells in Nudt15R138C knock-in mice. Leukemia 2020;34:882-894.

27. Cai JP, Ishibashi T, Takagi Y, Hayakawa H, Sekiguchi M. Mouse MTH2 protein which prevents mutations caused by 8-oxoguanine nucleotides. Biochem Biophys Res Commun 2003; 305:1073-1077.

28. Chang JY, Park SJ, Jung ES, et al. Genotype-based treatment with thiopurine reduces incidence of myelosuppression in patients with inflammatory bowel diseases. Clin Gastroenterol Hepatol. [published online ahead of print August 22, 2019]. https://doi.org/10.1016/j.cgh.2019.08.034.

29. Lee JH, Kim TJ, Kim ER, et al. Measurements of 6-thioguanine nucleotide levels with TPMT and NUDT15 genotyping in patients with Crohn's disease. PLoS One 2017;12:e188925.

30. Kakuta Y, Naito T, Onodera M, et al. NUDT15 R139C causes thiopurine-induced early severe hair loss and leukopenia in Japanese patients with IBD. Pharmacogenomics J 2016;16: 280-285.

31. Sato T, Takagawa T, Kakuta Y, et al. NUDT15, FTO, and RUNX1 genetic variants and thiopurine intolerance among Japanese patients with inflammatory bowel diseases. Intest Res 2017; 15:328-337.

32. Chao K, Wang X, Cao Q, et al. Combined detection of NUDT15 variants could highly predict thiopurine-induced leukopenia in Chinese patients with inflammatory bowel disease: a multicenter analysis. Inflamm Bowel Dis 2017;23:1592-1599.

33. Sutiman N, Chen S, Ling KL, et al. Predictive role of NUDT15 variants on thiopurine-induced myelotoxicity in Asian inflammatory bowel disease patients. Pharmacogenomics 2018;19: 31-43.

34. Shah SA, Paradkar M, Desai D, Ashavaid TF. Nucleoside diphosphate-linked moiety X-type motif 15 C415T variant as a predictor for thiopurine-induced toxicity in Indian patients. J Gastroenterol Hepatol 2017;32:620-624.

35. Suarez-Kurtz G, Brisson GD, Hutz MH, Petzl-Erler ML, Salzano FM. NUDT15 polymorphism in native American populations of Brazil. Clin Pharmacol Ther 2019;105:1321-1322.

36. Jarrar YB, Ghishan M. The nudix hydrolase 15 (NUDT15) gene variants among Jordanian Arab population. Asian Pac J Cancer Prev 2019;20:801-808.

37. Moriyama T, Nishii R, Perez-Andreu V, et al. NUDT15 polymorphisms alter thiopurine metabolism and hematopoietic toxicity. Nat Genet 2016;48:367-373.

38. Walker GJ, Harrison JW, Heap GA, et al. Association of genetic variants in NUDT15 with thiopurine-induced myelosuppression in patients with inflammatory bowel disease. JAMA 2019; 321:773-785.

39. Kakuta Y, Kinouchi Y, Shimosegawa T. Pharmacogenetics of thiopurines for inflammatory bowel disease in East Asia: prospects for clinical application of NUDT15 genotyping. J Gastroenterol 2018;53:172-180.

40. Kakuta Y, Kawai Y, Okamoto D, et al. NUDT15 codon 139 is the best pharmacogenetic marker for predicting thiopurineinduced severe adverse events in Japanese patients with inflammatory bowel disease: a multicenter study. J Gastroenterol 2018;53:1065-1078.

41. Akiyama S, Matsuoka K, Fukuda K, et al. Long-term effect of NUDT15 R139C on hematologic indices in inflammatory bowel disease patients treated with thiopurine. J Gastroenterol Hepatol 2019;34:1751-1757. 